\title{
Responsibility And Accountability: Towards An Integrative Process Model
}

Harald Bergsteiner, Macquarie Graduate School of Management, Australia

Gayle C. Avery, (E-mail: Gayle.Avery@gsm.mq.edu.au), Macquarie Graduate School of Management, Australia

\begin{abstract}
Accountability is increasingly critical for individual managers, company directors and board members, as well as for organizational operations. Despite growing attention in the literature, accountability processes are generally poorly understood and under-researched. This paper seeks to clarify the concepts of responsibility and accountability, and show how they relate to each other. The Integrative Responsibility and Accountability Process Model proposed here integrates responsibility and accountability processes from the viewpoint of both accountor and accountee. It is intended to be applicable at both individual and group levels in organizational settings.
\end{abstract}

\section{Introduction}

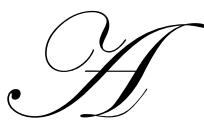

ccountability is widely considered to be a highly important organizational issue, increasingly critical for company directors and boards (Finkelstein \& Hambrick, 1996), managers, auditors, healthcare and financial services providers, and organizations that impact the environment and society generally (Akula, 2000). The distinction between accountability and responsibility is frequently unclear, and not surprisingly, responsibility and accountability processes are poorly understood, under investigated and under conceptualized (Cummings \& Anton, 1990; Frink \& Klimoski, 1998).

The growing importance of accountability in organizations and society generally, is paralleled in the literature. A 1998 literature review yielded fewer than 50 references, approximately half of which originated from five investigators and their colleagues (Frink \& Klimoski, 1998). One year later, Lerner \& Tetlock (1999) had identified 116 scholarly publications bearing accountability in the title.

Notwithstanding the surge of academic interest, substantial conceptual disagreement remains in the responsibility and accountability literature. This derives to some extent from the different focuses that people adopt with respect to the parties involved, and the objectives to be achieved. For example, different writers propose a unitary concept of responsibility (Cummings \& Anton, 1990), two key dimensions (Faust, Lyles \& Phillips, 1998), or up to six kinds of responsibility (Schlenker, 1997). Opinions diverge on the meaning and nature of responsibility and accountability (eg Cummings \& Anton, 1990; Ferris, Mitchell, Canavan, Frink, \& Hopper, 1995; Lerner \& Tetlock, 1999; Schlenker, 1997).

Accountability research tends to focus either at a general organizational level or on specific accountability issues where one party is accountable to another. Each of these foci can be examined in terms of the purpose of accountability; operations, processes and systems relating to accountability; and the effects of accountability. While recognising the importance of broader organizational accountability objectives and of unplanned accountability effects, the emphasis of this paper is on accountability exchanges between any two parties finding themselves in an accountability relationship. That is, the focus is on accountability exchanges between specific parties, rather than the broader organizational view of accountability.

In this paper, we introduce a graphical model that depicts the accountability and responsibility processes at

Readers with comments or questions are encouraged to contact the authors via email. 
both individual and group levels: the Integrative Responsibility and Accountability Process Model. In the following sections, we examine the responsibility and accountability processes using this model. Each part of the model is described using the existing literature, after introducing some basic terms.

\section{Basic terms}

We introduce two fundamental terms - accountor and accountee. The accountee is the person who is accountable to the accountor. These terms are intended to be hierarchically neutral, and non-value laden - after all a $\mathrm{CEO}$ is accountable to her staff just as they may be to her.

Many authors focus primarily on the accountee, but we argue that to properly understand and explain accountability processes one needs to include both the accountor and the accountee.

Several other terms require definition:

Accountability exchange, the specific situation where an accountee is being held accountable by an accountor, or holds himself/herself accountable vis-à-vis an accountor.

Accountability process, the generic process that typically occurs in any accountability exchange, concepts that attach to different parts of this process, and how they interact with one another.

Accountability system, the specific accountability processes and procedures that particular organizations may have in place.

Accountability relationship, the condition where one party may, at some point, need to account to another party, or where one party may, at some point, hold itself accountable vis-à-vis another party.

Accountability response, the generic term for rewards, feedback, counselling, sanctions and punishments applied as a result of an accountability exchange.

Further, we argue that accountability exchanges are triggered by:

- $\quad$ Actions (this includes behaviors, and implemented decisions and choices);

- Consequences (this includes outcomes and results, whether actual or anticipated); and

- Intentions (an unethical action that produces a positive consequence may trigger an accountability exchange by virtue of the fact that it was unethical).

\section{Integrative Responsibility And Accountability Process Model}

The Integrative Responsibility and Accountability Process Model (see Figure 1) reflects our view that responsibility and accountability are separate processes, with responsibility preceding accountability. Various kinds of responsibility and accountability can be identified at different points in the model, from the perspective of both accountor and accountee. To establish a context for the remainder of this paper, the model is described first in broad terms, followed by more detailed discussion of its individual components.

The model reflects two domains. Above the dotted horizontal line is the external domain, which refers to processes affecting or emanating from the accountor. Below the dotted line are processes relating to the accountee, said to be in the internal domain. Along the dotted line, a series of boxes labelled 1 through to 6 and the arrows linking them show the interactive nature of the typical accountor/accountee exchange in action. The boxes numbered 1 to 4 , and the arrows linking them, show the interactive nature of the typical accountor/accountee exchange as they relate to responsibility. Below the boxes are internal responsibilities that impact on the accountee, and internal re- 
sponsibilities that arise out of the process. Above the boxes are external responsibilities that impact on the accountee, and external responsibilities that arise out of the process.

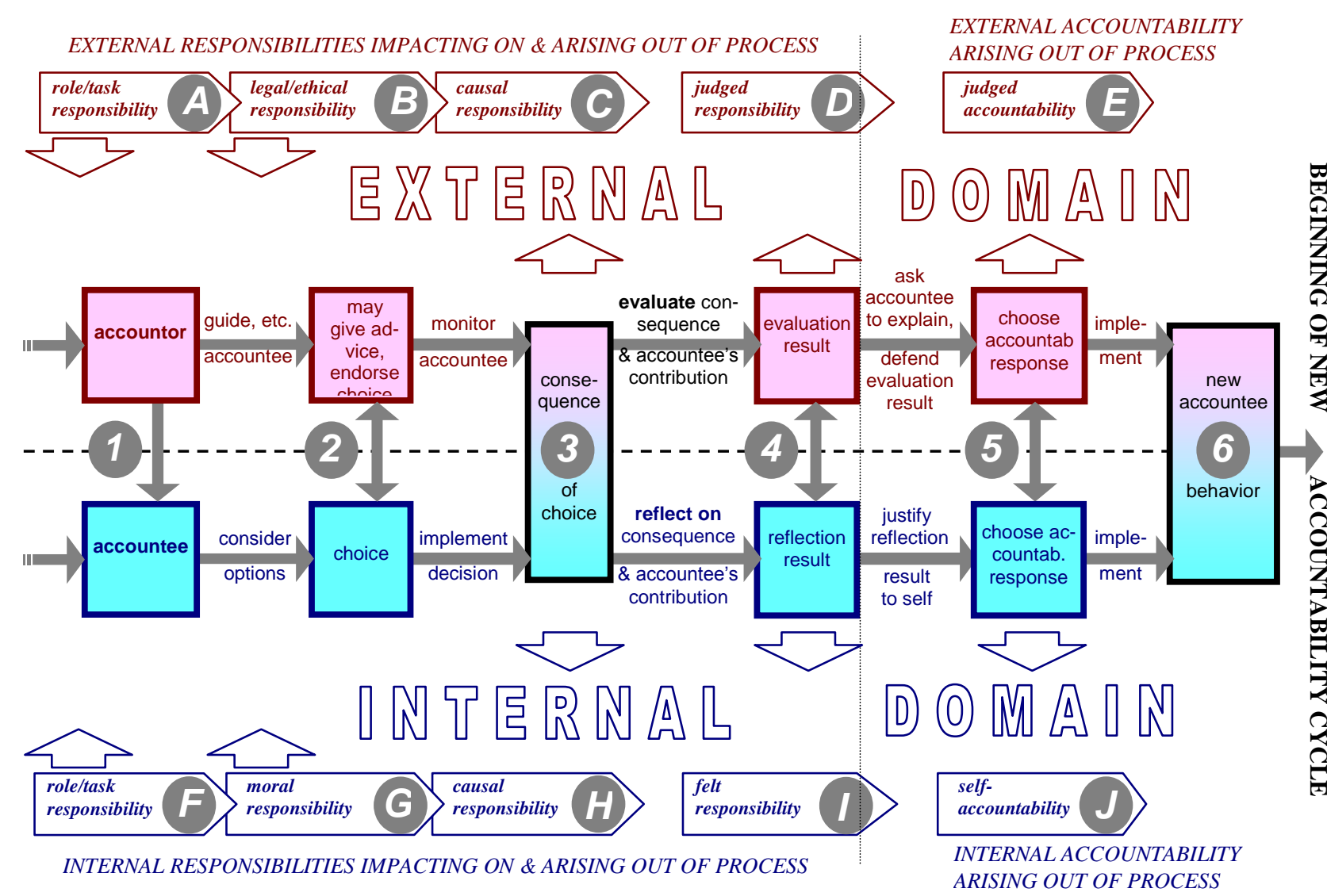

Figure 1: Integrative Responsibility and Accountability Process Model

Figure 1 shows that accountability continues from where the responsibility process ends, the accountability episode terminating at 6 . Again, below the boxes are internal accountabilities that arise out of the process for the accountee, and above the boxes are external accountabilities that arise out of the process for the accountee.

At Stage 1, the accountee will have a role assigned by an external party, say that of marketing manager, or will volunteer for a role. Since the role has an impact upon the accountee, the vertical arrows are pointing towards the accountee. This accountee is required to perform some task, make a decision, or perhaps solve a problem. Normally, an accountee considers various options, but eventually makes a choice (Stage 2) about what to do, when and how. The choice is influenced by legal and ethical constraints from the external world (laws, rules, company policies, social norms etc.), and by internal moral constraints (vertical arrows point towards the accountee). Having made a choice, the accountee implements the decision or engages in the preferred behavior to produce a consequence (Stage 3).

When a consequence can be attributed to an accountee, s/he is said to carry causal responsibility for it. We argue below that the consequence gives rise to the notion of causal responsibility, so the vertical arrows are now reversed, ie causal responsibility does not impact on the consequence, but flows from it. The consequence is then evaluated by an external party and/or reflected upon by the accountee, to produce an evaluation result and/or reflection result (Stage 4). An assessment of the relative importance of the accountee's role/task, legal/ethical/moral and 
causal responsibilities leads to judged responsibility. Here too, the vertical arrows point away from the result.

Similarly, in the internal domain, the accountee's reflection process gives rise to felt responsibility. The vertical dotted line marks the boundary between the responsibility and the accountability episodes.

The accountability episode begins immediately following the evaluation result at Stage 4, the last stage of the responsibility episode. Here, in the external domain, the accountee may be called upon to explain, justify or defend poor results to the accountor - usually there is little need to explain, justify or defend desired results. Second, the accountee may attempt to justify the result to him/herself to determine whether, and to what extent, to hold $\mathrm{him} / \mathrm{herself}$ accountable. At the next stage of the accountability response, others and/or the accountee will decide how the accountee will be held, or hold him/herself, accountable. The preferred response option(s) will then be implemented, leading to the accountee's future behavior.

Below, we describe the key elements of the model in more detail, starting with responsibility.

\section{Responsibility}

Creating a single, all-purpose definition of responsibility is prone to lead to confusion because six quite distinct concepts of responsibility have a place in accountability theory. Four singular concepts of responsibility role/task responsibility, ethical/legal responsibility, moral responsibility and causal responsibility - interact to give rise to two hybrid concepts of responsibility - judged responsibility and felt-responsibility. In the vernacular, people sometimes use the term "felt responsibility" to describe a situation whereby they, or others, feel the obligation to perform some future task, solve some problem etc. We argue that this concept is, in fact, an amalgam of role/task and legal/ethical/moral responsibility. For example, a mother "feels responsible" for the well-being of her child thus part of her role is to provide her child with food, and she has a legal and moral duty to do this.

Role/task, moral and legal/ethical responsibility are, in effect, inputs brought to a situation, eg before people consider doing something, they usually already have a role, and are subject to moral, ethical and legal imperatives. In contrast, causal, felt and judged responsibility can only be determined after some consequence has occurred, and are regarded as outputs of an accountability exchange, taking a fundamentally different place in any accountability system or process.

The relationship between these six forms of responsibility is shown in the Integrative Responsibility and Accountability Process Model (Figure 1). Below, each step of the model is discussed in turn, and the relevant part of the model is depicted next to the text for clarity.

\subsection{The accountee - Role/task responsibility}

Role/task responsibility is defined as a product of social roles that one acquires or chooses to accept, implying duties and obligations arising from the proper performance of the role and from group membership. Role/task responsibility, and concomitant accountability, is usually understood to be attached to particular tasks assigned to, or carried out by, people. The concepts of role and task are closely linked, although two account managers in a firm servicing different clients can have the same role responsibility, but different task responsibilities. Tasks are of a lower order category than roles. Role/task responsibility has limits, and can be diluted (see below).

\subsection{The choice - Legal/ethical and moral responsibilities}

Ethical/legal and moral responsibility derive from the requirement to make behavior, decisions and choices subject to legal, ethical and moral rules of conduct. Ethical/legal responsibility occurs in the external (accountor) domain, moral responsibility

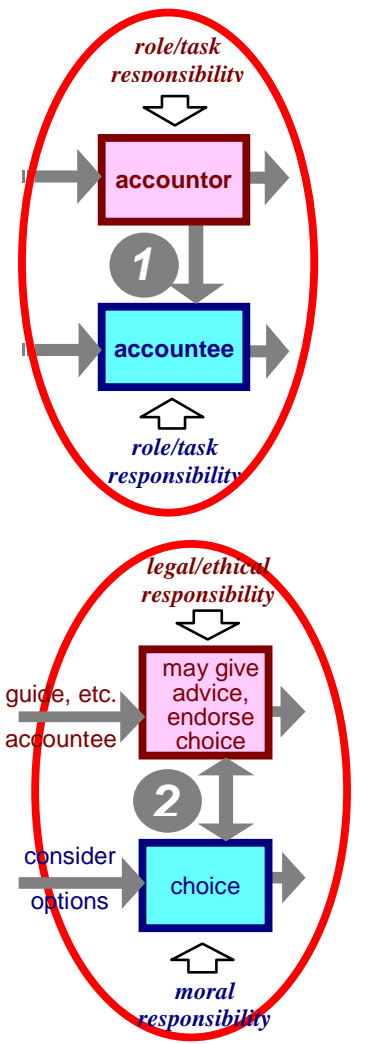


occurs in the internal (accountee) domain.

Both kinds of responsibility influence choice, and in some circumstances, people may have legal/ethical or moral responsibility but no role/task responsibility, eg patients of a hospital could be argued to have certain ethical and moral obligations vis-à-vis other patients, but no role/task responsibility. For the purposes of a responsibility/ accountability system, the single most distinguishing feature between moral issues on the one hand, and legal/ethical issues on the other, is that legal/ethical issues provide external checks and guidelines on behavior, whereas moral issues tend to be internally focused.

Law can be seen to depend for its effectiveness most heavily on force (with the severity of the punishment reflecting the seriousness of the transgression). Ethics derives from education, membership of a society or other group, and is associated with potential ostracism; while morality is based around membership of a society or other group, and potential shame (Koniac, 1996). It is noteworthy that ostracism happens very much in the public or external domain, while shame operates very much in the private or internal domain. This is consistent with the allocation of ethical/legal responsibility and moral responsibility into public and private domains.

\subsection{The consequence - Causal responsibility}

Consequences can display a number of characteristics: quality (extremely negative, through neutral, to highly positive), significance (highly significant to negligible), frequency (once only to repeated), and reversibility (fully reversible to irreversible). The definition of a positive consequence is one that meets or exceeds requirements. Thus a loss in a start-up company that is smaller than was planned for and expected, would be regarded as a positive consequence. People aim for, or are meant to aim for, positive consequences. The achieving, or not, of such consequences is assessed in the light of the consequence itself, the action and factors that led to it (there may be multiple causes), and the intentions that guided that action (whether it was ethical or not). Causal responsibility relates to whether a person(s) caused a consequence to occur, precipitated it, or contributed to it.

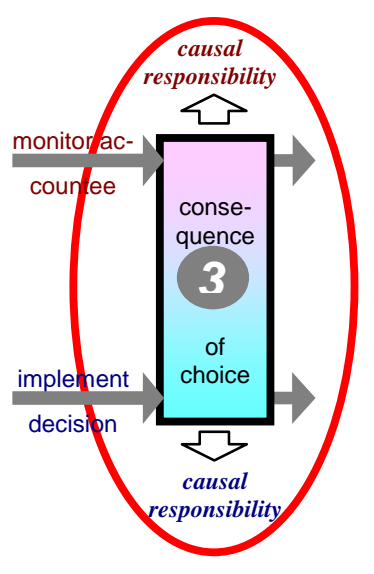

\subsection{Evaluation and reflection process}

The accountor will evaluate the consequence of a decision or choice, and the accountee's contribution to the consequence. Note that at this stage, the focus is solely on obtaining an evaluation result that describes the accountee's effort in achieving the consequence. The accountee has not yet been asked to explain, justify or defend anything.

How soon or how frequently the accountor evaluates the accountee's performance depends on factors like the nature of the task (ongoing, to a once-only evaluation; easy to complicated); the importance of the task (critical to survival of organization, to marginal); and the competency of the person (greenhorn to expert). Evaluation may be informal or formal, eg using performance management, written contracts or other tools. Evaluating an accountee's contribution to the consequences can be difficult in the absence of suitable measures (Gallo \& Thompson, 2000).

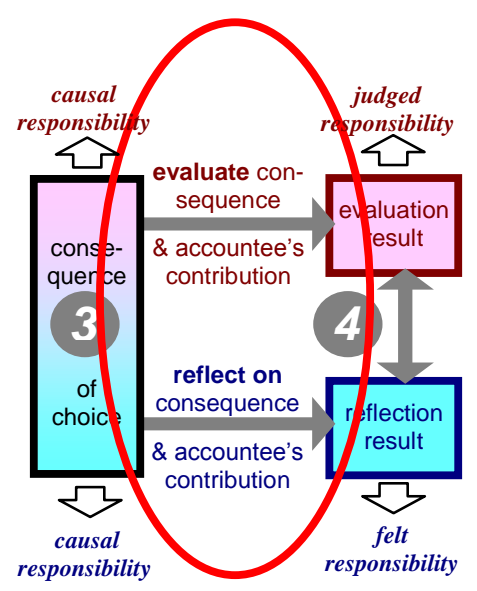

An accountee also reflects on the consequence to assess the extent to which s/he performed according to external criteria such as goals, targets, objectives, laws, contractual obligations, job description, procedures, policies, union rules, or work practices. Internal criteria the accountee can apply during reflection include ethics, morals, values, personal targets, professional norms, and the accountee's perceived social role and ideological fit with the situation. An accountee's perceptions about a consequence can range from highly 
positive to highly negative. These perceptions can be influenced by the relative personas of accountor(s) and accountee, their relationship, and situational factors, such as the perceived degree of interference from the accountor or others, adequacy of resources, and organizational culture and norms (Frink \& Klimoski, 1998). In organizations with a pronounced blame culture, people's preparedness to take risks is likely to be diminished, as people try to protect themselves from anticipated negative consequences.

\subsection{The evaluation result - Judged and felt responsibility}

Note that unlike the consequence, which is shown in a single box, the evaluation result and the reflection result are shown in different boxes. This reflects the fact that objectively the consequence will be the same for the accountor and the accountee (so many widgets made, so many contacts made, etc.). However, perceptions as to the meaning of the consequence can vary dramatically (the same consequence may be perceived as a reasonable result by one party, whereas another may see it as deficient).

Judged responsibility reflects the combination of role/task, ethical/legal, moral and causal responsibility. We coined this term to refer to the extent to which a person(s) is judged responsible for the consequence of a decision or action. This judgement takes into consideration the contribution the person(s) made to the consequence (causal responsibility); the person's role (role/task responsibility); legal, ethical and moral issues (legal/ethical and moral responsibility); and any factors that may dilute, or make one or more of these responsibilities irrelevant.

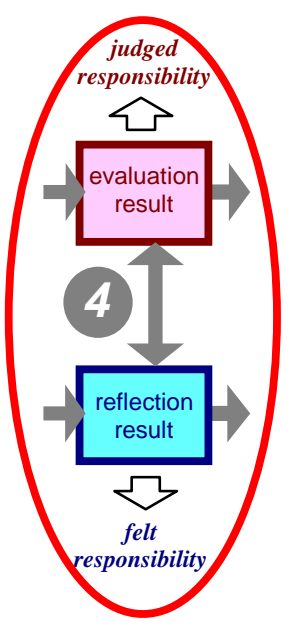

Following a consequence, accountors raise questions, whose answers become inputs into, and may dilute, judged responsibility considerations (Schlenker, 1997), eg:

- Was the decision/choice or action defensible?

- What were the role/task, legal/ethical, moral and causal responsibilities of the person who occasioned the consequence?

- Would any factors dilute, or render irrelevant, one or more of these responsibilities?

Dilution affects role/task, ethical/legal, moral and causal responsibility, although some writers argue that accepting role/task responsibility precludes dilution of that responsibility (Cummings \& Anton, 1990). Others concur that responsibility can be diluted, eg role/task responsibility can be diluted by:

- $\quad$ Sharing responsibility (usually horizontally eg via teamwork);

- $\quad$ Devolution (vertically eg through delegation); or

- Dispersion (horizontally eg making managers responsible for the HR function and abolishing the central HR group).

Ethical/legal and moral responsibility can be diluted eg legal systems consider what a person could reasonably have been expected to know or understand in a particular circumstance. However, people can be held morally responsible for acts of their organization, such as poisoning drinking water supplies or selling toxic products. The moral responsibility stems from people not exercising their choice not to be part of that organization (Fischer, 1999).

Causal responsibility can be diluted, eg in organizations that 'shoot the messenger' of bad news, executives would be understandably reluctant to speak up, even when the enterprise as a whole is in danger. Here, the culture constrains responsibility and accountability, even though the managers' silence could cause harm to the organization.

In complex organizations, a perceived dilution of responsibility occurs through the "problem of many hands" (Bovens, 1998). Here, it becomes difficult to either attribute responsibility to such organizations as a whole, or to hold specific individuals responsible. 
Felt responsibility refers to an accountee's cognitive and emotional acceptance of having contributed to, or caused, a consequence, taking into consideration role/task, legal/ethical, moral and causal responsibility, and diluting or mitigating factors.

Felt responsibility parallels judged responsibility except that it involves consideration of one's own perceived contribution, rather than having one's contribution judged by others. Whilst a group (eg an autonomous team) can be judged collectively responsible for a particular consequence, irrespective of each individual group member's feelings, only individual members can feel responsible. If sufficient group members share these feelings of responsibility, the rest of the group may concur in any self-accountability measures, although some individual members may not feel personally responsible.

Clearly, many attributions, defence mechanisms, attitudes, values and other personal factors influence the degree of felt responsibility. It should be noted that felt responsibility is not synonymous with holding moral values, eg most members of the Cosa Nostra are perfectly able to decide when it is opportune to brag about a crime ("I did it and I'm proud of it" - felt responsibility) and when it is better to deny it (eg to police!). Here, felt responsibility is acknowledged or denied depending on the circumstances.

So far, we have seen how the combination of role/task, ethical/legal, moral and causal responsibility leads to judged responsibility from external parties, and felt-responsibility arising from internal reflection. At this stage, we have covered only responsibility, which many writers regard as a sub-set of accountability (eg Cummings \& Anton, 1990).

However, we argue that responsibility precedes accountability. This is consistent with common parlance, where responsibility is implied to occur before accountability. For example, a public transport authority CEO is quite likely to say to his/her operations chief: I'm making you responsible for getting the trains to run on time - and I'm going to hold you accountable, if they don't. It would be semantically contrived, if not nonsensical, to say: I'm making you accountable for getting the trains to run on time - and I'm going to hold you responsible, if they don't.

Once judged responsibility has been established, the accountability process can begin. Felt responsibility may or may not apply at this stage.

\section{Accountability}

Following the last stage of the responsibility episode, ie the evaluation result at Stage 4 of the Integrative Responsibility and Accountability Process Model (Figure 1), the accountability episode begins between Stages 4 and 5. The discussion below explains the concepts of judged accountability and self-accountability, but first we consider the concept of mitigating circumstances.

\subsection{Mitigating circumstances - Explaining, justifying and defending evaluation/reflection result( $(s)$}

Evaluation and reflection results arise from the two parties' deliberations, which may not be in agreement. From the accountor's perspective, once an evaluation result of the accountee's efforts has been obtained, the accountee may or may not be called upon to explain, justify or defend the result. From the accountee's point of view, evaluation and reflection results may need reconciling or, when substantial differences are apparent, a decision needs to be made on how to deal with the situation. An accountor will examine whether an accountee can validly be held accountable for a particular consequence, which will depend upon whether any mitigating circumstances operate. Mitigating circumstances include unforseen external circumstances, insufficient resources, complex new procedures, etc.

Further, there are three conditions when it is not reasonable to hold

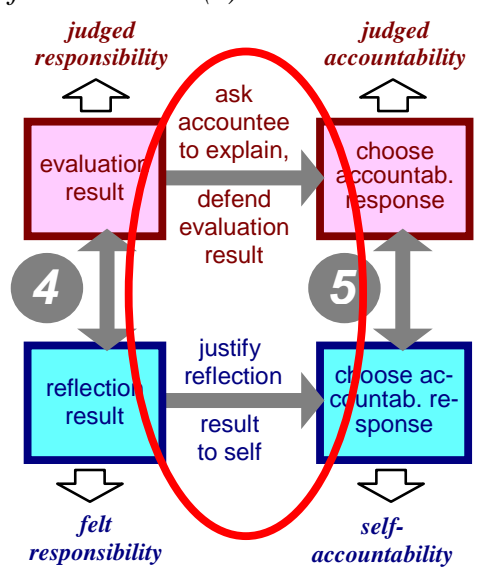


someone accountable.

These are:

- When there is a lack of capacity for rational behavior,

- When the condition of foreseeability is not given, and

- When behavior is not volitional.

The capacity for rational behavior refers to whether the accountee's mental or psychological state departed from that of a 'normal adult' at the time of the event. Diminished capability for rational behavior (through mental deficiency, illness or immaturity) reduces the extent to which a person can be held accountable for their actions.

Foreseeability is concerned with whether a rational person could have foreseen the condition, rather than with whether a given accountee did actually foresee the consequence (Cummings \& Anton, 1990). A challenge for accountors is to differentiate between behavior that is merely an excuse, such as "I could not have known" (Markman \& Tetlock, 2000), and behavior that reflects a genuine inability to have foreseen a consequence.

The volition argument holds that a person ought only to be held accountable for volitional acts, ie not acts beyond the person's control or executed under duress. Further, while the notion that less deliberation (implying less intent) necessarily leads to less judged responsibility seems to hold in criminal cases, in an organization it is likely to be an exacerbating factor. For example, an IT department that recommends an ill-suited IT system cannot claim lack of deliberation as a mitigating factor. In fact, the less deliberation, the greater the judged responsibility for the failure.

Furthermore, it has been suggested that people should only be held accountable when routine expectations are violated or when deviations from the norm occur (Cummings \& Anton, 1990; Schlenker, 1997; Semin \& Manstead, 1983). However, a focus on deviations for holding people accountable seems to ignore the consequences for people who are simply doing their job. Grossly oversimplified one could say that underperformers lose their jobs, steady performers keep theirs, and superior performers are promoted. In each case there is an outcome for the accountee, and, by definition, the fact that there is an outcome (eg not being promoted) means that people are being held accountable. We also wonder how an employee who consistently meets others' high expectations (ie there is no deviation from standards) would react if there were no occasional rewards, even if these only take the form of praise. Clearly, accountability can arise under alignment with, as well as deviation from, the norm.

\subsection{The accountability response - Judged and self-accountability}

Judged accountability is done by another (or others) applying relevant behavioral modification/maintenance tools (the accountability response) and, where appropriate, the calling to give account (excuses, explanations or justifications) to another (or others) for a consequence, and for how this consequence came about. Accountability responses can take many different forms, ranging from substantial rewards, through feedback and counselling, to severe punishment. A major issue is how to determine the appropriate accountability response.

In brief, within the context of an accountability system it is insufficient to determine mere causal responsibility, one needs to consider the actual consequences and the overall context in which they arose. Various external influences affect an accountability response, such as the value and magnitude of rewards and sanctions, nature of the mistake/failure or achievement, the extent to which others are aware of an accountability situation, past history of accountability exchanges, and the gravity of the consequence. Internal influences like personal and attributional factors, emotional maturity, locus of control, level of initiative, and reward focus, affect the explanations and justifications people proffer when faced with an evaluation result.

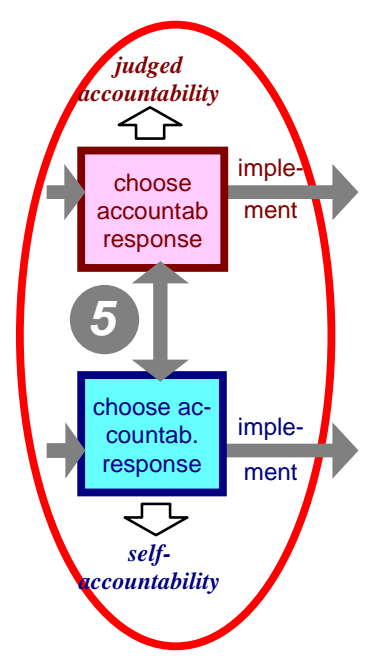


Self-accountability refers to behavior applied to the self, and involves self-evaluation of behavior and its consequence, and making voluntary changes to behavior (Dose \& Klimoski, 1995). Individuals may seek or selfadminister rewards, sanctions or feedback based on progress towards goal attainment. In some situations, selfaccountability may not be entirely voluntary, but people are "allowed", "encouraged", or perhaps even "required", to exercise self-accountability in order to allow them to save face, or avoid protracted legal proceedings. Selfaccountability is also culturally determined. For example, Lord Carrington's resignation as British Foreign Secretary the day after the Argentines occupied the Falkland Islands compares with his US counterparts, who apparently did not accept responsibility in the same situation (Cummings \& Anton, 1990). Lord Carrington's resignation is a striking example of self-accountability in action, which presupposes that there was felt responsibility.

\subsection{Accountee's future behavior}

The final stage of an accountability exchange is an accountee's future behavior, which can take the form of:

- $\quad$ Same behavior continues (accountee maintains desirable behavior),

- $\quad$ Existing behavior is discontinued (accountee ceases undesirable behavior and learns not to repeat it),

- New behavior is acquired (accountee engages in new desirable behavior and learns to repeat it).

\section{Linking Responsibility And Accountability}

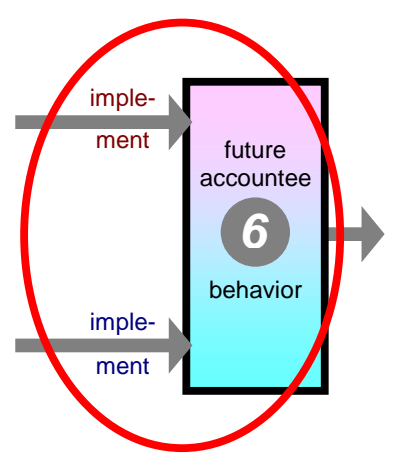

In the model, we have identified the responsibility and accountability processes (eg how an accountee looks at options, makes a choice, implements it, and brings about a consequence), and shown how these processes relate to different concepts of responsibility and accountability (role/task, legal/ethical, moral, judged and felt responsibility; and judged and self-accountability). In Figure 1, the Integrative Responsibility and Accountability Process Model depicts how the responsibility and accountability concepts and sub-models can be integrated into one process.

The upper part of the Integrative Responsibility and Accountability Process Model represents the external or accountor domain, includes judged responsibility and judged accountability. Both of these terms describe observable behavior that can be objectively measured. Judged responsibility is what a person is judged on; judged accountability is how a person is dealt with by others as a result of a consequence of his/her actions. Essentially, the external domain illustrates an organization's approach to accountability.

The lower part of the Integrative Responsibility and Accountability Process Model represents the internal or private (accountee) domain, which includes felt responsibility and self-accountability. Both of these terms refer to an internal cognitive and emotional state, and describe individual perceptions that may be subjective. Felt responsibility refers to an evaluation of a person's own contribution towards a consequence, whereas self-accountability is how the person acts upon a consequence of his/her actions. This is also the domain that concerns the accountee's willingness to be held accountable.

From Figure 1, we can see that through an evaluation process, the combination of A (role/task responsibility) with B (legal/ethical responsibility) and C (causal responsibility) gives rise to D (judged responsibility), which in turn may give rise to $\mathrm{E}$ (judged accountability). It does not make sense for $\mathrm{E}$ to occur before $\mathrm{D}$, ie for someone to be held accountable who has not been judged responsible (dysfunctional relationships excepted). Similarly, through a reflection process, the combination of $\mathrm{F}$ (role/task responsibility) with $\mathrm{G}$ (moral responsibility) and $\mathrm{H}$ (causal responsibility), gives rise to I (felt responsibility), which in turn may give rise to J (self-accountability).

Again, it does not make sense for $\mathbf{J}$ to occur before $\mathrm{I}$, ie for someone to hold themselves accountable for something they do not feel responsible for (dysfunctional personalities excepted). Further, we would argue that judged accountability is more likely to find acceptance on the part of an accountee in the presence of felt responsibility (Collins \& Hoyt, 1972). 


\section{Conclusion}

The hope is that the concepts and processes depicted in the Integrative Responsibility and Accountability Process Model will help reduce confusion in future discussions on accountability and responsibility, and will stimulate further research into responsibility and accountability processes.

Clearly, additional features need to be incorporated into the Integrative Responsibility and Accountability Process Model. Many factors influence the accountability exchange process (Lerner \& Tetlock, 1999), but for the purposes of simplicity and meeting length considerations, we have chosen to merely indicate the general nature of these moderating variables.

The Integrative Responsibility and Accountability Process Model allows for multiple constituencies, although showing specific multiple constituents in the model has been omitted here. In any accountability exchange, the relationship between different constituents can be the focus of the accountability process, but only one exchange has been the focus here to simplify the model.

Further features that the model needs to take into account include the mutual influencing processes between accountor and accountee that occur at various stages of the process, and at times involve others in the organization. A mutual influence model has already been developed and described elsewhere, but is beyond the scope of this paper.

\section{References}

1. Akula, J.L. (2000) Business crime: What to do when the law pursues you, Sloan Management Review, spring, 41 (3), 29-41.

2. Bovens, M. (1998) The Quest for Responsibility: Accountability and Citizenship in Complex Organisations, Cambridge University Press.

3. Collins, B.E. \& Hoyt, M.F. (1972) Personal responsibility-for-consequences: An integration and extension of the forced compliance literature. Journal of Experimental Social Psychology, 8, 558-593.

4. Cummings, L.L. \& Anton, R.J. (1990) The logical and appreciative dimensions of accountability, in S. Srivasta \& D. L. Cooperrider and Associates (Eds.), Appreciative Management and Leadership: The Power of Positive Thought and Action in Organizations, San Francisco: Jossey-Bass, pp. 257-286.

5. Dose, J.J. \& Klimoski, R.J. (1995) Doing the right thing in the workplace: Responsibility in the face of accountability, Employee Responsibilities and Rights Journal, 8 (1), 35-36.

6. $\quad$ Faust, G.W., Lyles, R.I. \& Phillips, W. (1998) Responsible Managers Get Results: How the Best Find Solutions - Not Excuses, AMACOM, New York: American Management Association.

7. Ferris, G.R., Mitchell, T.R., Canavan, P.J., Frink, D.D. \& Hopper, H. (1995) Accountability in human resources systems, in Ferris, G.R., Rosen, S.D. \& Basman, D.T. (Eds), Handbook of Human Resource Management, Oxford: Blackwell Business, pp.175-196.

8. Finkelstein, S. \& Hambrick, D.C. (1996) Strategic Leadership: Top Executives and Their Effects on Organizations, Minneapolis: West Publishing Company.

9. $\quad$ Fischer, J.M. (1999) Recent work on moral responsibility, Ethics, Oct, 110 (1), pp. 93ff.

10. Frink, D.D. \& Klimoski, R.J. (1998) Toward a theory of accountability in organizations and human resource management, Research in Personnel and Human Resources Management, 16, 1-51.

11. Gallo, J. \& Thompson, P.R. (2000) Goals, measures, and beyond: In search of accountability in federal HRM, Public Personnel Management, 29 (2), 237-248.

12. Koniac, S. (1996) Law and ethics in a world of rights and unsuitable wrongs, Canadian Journal of Law and Jurisprudence 9(11), 21.

13. Lerner, J.S. \& Tetlock P.E. (1999) Accounting for the effects of accountability, Psychological Bulletin, $125,(2), 255-275$.

14. Markman, K.D. \& Tetlock, P.E. (2000) 'I couldn't have known': Accountability, foreseeability and counterfactual denials of responsibility, British Journal of Social Psychology, 39, 313-325.

15. Schlenker, B. (1997) Personal responsibility: Applications of the Triangle Model, Research in Organizational Behavior, 19, 241-301.

16. Semin, G.R. \& Manstead, A.S.R. (1983) The Accountability of Conduct: A Social Psychological Analysis, London: Academic Press. 